\section{Evaluation of seafood traceability system in Korea: demand-oriented analysis}

\author{
David Suh, ${ }^{1}$ Robert Pomeroy ${ }^{2}$
}

${ }^{1}$ Department of Agricultural and Resource Economics, University of Connecticut, Storrs, CT; ${ }^{2}$ Department of Agricultural and Resource Economics, Connecticut Sea Grant, University of Connecticut at Avery Point, Groton, CT, USA

\begin{abstract}
The Korean government tried to secure food safety by revitalization of seafood traceability system since there has been growing dissatisfaction toward of food system related to seafood in Korea. This study examines the consumers' perspective on seafood traceability system and the value of seafood traceability in Korea using contingent valuation method. The model includes preference and recognition of respondents for the seafood traceability system, and socio-demographic characteristics. The result of the model shows that respondents think positively about seafood traceability system and it is expected that approximately $\$ 44.94$ million can be generated annually from the seafood traceability system. The result implies that it is necessary to promote the system in order to make this system known, the benefit of which is helpful in food safety.
\end{abstract}

\section{Introduction}

People in Korea, which is surrounded by ocean on three sides, are familiar with seafood, and seafood has traditionally been one of the most widely loved foods in Korea. Seafood has become increasingly popular over time in line with awareness that it is rich in protein and essential nutrition, such as omega 3 fatty acids and calcium, needed for a healthy body. As a result, consumption of seafood in Korea is constantly increasing and Korea has become one of the world's largest seafood consumers (FAO, 2018).

However, despite the high level of consumption of seafood, there has been growing dissatisfaction with the food system in Korea, particularly in relation to food safety, because the system has not been well developed when compared to other major seafood consuming countries. Quality and safety are two important factors for consumers in terms of perceptions and decision making on choice and purchase of food (Van Rijswijk et al., 2008). The Korean government is attempting to secure these factors by revitalizing the seafood traceability system and is planning a pilot project for a mandatory seafood traceability system from December 2018 to the end of 2021 (MOF, 2018, Oct. 26).

In practice, seafood traceability gives consumers a sense of security in that it helps ensure the quality and lowers the risk of poor food safety. If accidents occur with regard to seafood, the information provided by traceability enables people to discover the cause of the problem, collect the problematic products to limit the damage, and facilitate an effective contingency plan and clarification of responsibilities (Leal et al., 2015). In addition, it is useful for the management of information in terms of the quality and cleanliness of seafood and enables producers to understand consumers' needs (Yasuda and Bowen, 2006). However, this system is not well-established in terms of producer participation or consumer awareness (Shin, 2018). From this point view, this paper examines the seafood traceability system from the consumers' perspective in Korea, taking notice of applicability of the system as a part of securing food safety. It is necessary to consider the effects of the preference for seafood and the awareness of seafood safety as part of understanding the system. The relationship between the preference for seafood and the value of a traceability system and the implications of the traceability system in connection with awareness of seafood safety are discussed in this paper.

\section{Seafood traceability}

The start of seafood traceability originated from the need for producers to facilitate the recall of fisheries products, allowing consumers to avoid foodborne illness (Caswell, 1998), but now the system is also led by government who cares for the safety of the citizen and retailers who want to attain good reputation in relation to food safety (Caswell, 1998; Van Rijswijk et al., 2008). A traceability system enables domestic producers to monitor and maintain good quality of seafood, and provides information by incorporating data from existing reporting systems to better understand regulatory requirements in import and export countries (Borit and Olsen, 2012). The system makes exporters abide by the strict policies of international seafood conventions, and takes a role in ensuring all producers follow all relevant regulations (He, 2018). Furthermore, the system contributes to controlling illegal, unreported and unregulated fishing and
Correspondence: Robert Pomeroy, 380 Marine Science Building 1080 Shennecossett Road, University of Connecticut - Avery Point, Groton, CT 06340, USA.

Tel.: +1.860.405.9215.

E-mail: robert.pomeroy@uconn.edu

Key words: Traceability system; seafood; food safety; contingent valuation.

Contributions: DS and RP have made a substantial contribution to the research work and they were both involved in the drafting and editing of the manuscript.

Conflict of interest: The authors declare no potential conflict of interest.

Funding: None.

Availability of data and materials: Data and materials are available in the text.

Received for publication: 12 April 2020.

Accepted for publication: 24 June 2020.

This work is licensed under a Creative Commons Attribution-NonCommercial 4.0 International License (CC BY-NC 4.0).

(C) Copyright: the Author(s), 2020

Licensee PAGEPress, Italy

Italian Journal of Food Safety 2020; 9:9021

doi:10.4081/ijfs.2020.9021

encourages trade in legally caught fish. A traceability system can limit the market for illegal fish and protect producers who are operating legally, preventing the importation and sale of illegally caught fish (Pramod et al., 2014). A well-established traceability system can raise the level of food safety even further and contribute to increases in consumer confidence in products in the long run (Van Rijswijk et al., 2008).

A seafood traceability system was introduced in Korea in 2008. It was implemented with 10 seafood items chosen and promoted by the MOF (Shin, 2018). Information about the stages of production, processing, and distribution is traceable by an identification number, which is indicated on the product or packaging with appropriate labeling. The National Fishery Product Quality Management Service manages the labeling system, and customers can access information using the internet or a mobile app (Shin, 2018). As of 2019, it applies to 52 kinds of products, including not only general marine products such as trout, flatfish, mackerel, cod, snapper, bass, anchovy and yellow corvina, but also to freshwater products such as loach and catfish. The problem is that the seafood traceability system is under-utilized as consumers of 
seafood have low awareness of the system and are not interested in utilizing it (MOF, 2015).

According to a survey of the general public conducted by the MOF, $27.3 \% \sim 39.7 \%$ of people know about the seafood traceability system (MOF, 2015). This figure stems from the low rate of participation in the system as the government implemented it on a voluntary instead of a mandatory basis, resulting in it being little more than a name rather than an understanding of its role and purpose.

According to the MOF, approximately ten thousand of a possible sixty thousand businesses, which encompass fish product production, processing, distribution and sales, participated in the seafood traceability system in 2016, with a participation rate of around $16.6 \%$. As of 2016, the items provided in the traceability system included sea mustard (4,478 metric ton), yellow corvina (2,393 metric ton), mackerel (1,653 metric ton), halibut (675 metric ton), cutlassfish (662 metric ton), and squid (576 metric ton). The identification number for traceability is indicated on 10,905 metric tons of products (MOF, 2018), and represents $22.82 \%$ of products targeted. Of the 3.27 million metric tons of products from fisheries in 2016, the percentage of traceable products to the total supply is less than $0.4 \%$ (MOF, 2018).

The Korean government is attempting to gradually enforce the system and expand the range of items, with a growing interest in seafood traceability and improvement in seafood safety, but it is necessary to support this with relevant research (MOF, 2016). However, Korea has a poor record in this regard as the traceability system has not advanced and lacks discussion on the value and promotion of the system, apart from acknowledging the need for the system. Accordingly, examination of the awareness and value of a seafood traceability system can help Korea understand and set the future direction for the system.

\section{Materials and Methods}

This paper applies the Contingent Valuation (CV) method to measure the value of seafood traceability in Korea, and performs the analysis on change in values. The CV method is an approach used to measure the value of goods when the price is not determined by eliciting WillingnessTo-Pay (WTP) for the goods in the hypothetical market (Ajzen \& Driver, 1992; Champ et al., 2003). If there is no surrogate market to estimate the value of the nonmarket goods, or the current market is limited to use information about the price, surveys are often the most effective way to derive consumer's preference (Champ et al., 2003), and the CV method has the advantage of directly obtaining a monetary measure of value (Ajzen and Driver, 1992; Hoyos and Mariel, 2010). The method began to be considered as an economic valuation tool in the US federal institutions in the 1970s, and has consolidated as a non-market valuation method in academic field from early $90 \mathrm{~s}$ (Hoyos and Mariel, 2010).

The method is based on welfare economics and the neoclassical concept of valuation under the utility maximization problem (Hoyos and Mariel, 2010). The theory starts with difference between the utility with current condition and the utility with new condition (Champ et al., 2003). Let $\mathrm{V}(\cdot)$ be indirect utility function and the value related with seafood traceability system take the form:

$V\left(S_{1}, I-C\right)=V\left(S_{0}, I\right)$

Where indicates the presence of the seafood traceability system, indicates the absence of the seafood traceability system, I is income, and $\mathrm{C}$ is Hicksian compensating surplus. If a respondent accepts the amount suggested in the discrete-choice question, then it implies the utility of the seafood traceability system is greater than the absence of the system. The deterministic system can be transformed into a stochastic model involving the probability of WTP :

$P_{\mathrm{y}}(\theta)=\mathrm{P}\left[\mathrm{V}\left(S_{1}, I-\theta\right)-\mathrm{V}\left(S_{0}, y\right)>u\right]$

where $\mathrm{P}(\cdot)$ is probability distribution function, $\theta$ is the suggested price which is a neutral stimulus and $\mathrm{u}$ is the error term (Boyle et al., 1997). Let $\Delta \mathrm{V}$ as the difference between and then the probability distribution function and cumulative distribution function take the form:

$$
P_{\mathrm{y}}(\theta)=\mathrm{P}\left[\Delta \mathrm{V}=\mathrm{V}_{S l}-\mathrm{V}_{S 0}>u\right]
$$

In this study, the cumulative distribution function of the standard normal distribution is used for the analysis. From the probability that respondent will pay, the distribution function of WTP values, $\mathrm{F}(\cdot)$ can be written:

$$
F(\Delta \mathrm{V})=[1+e(-\beta X)]^{-1}
$$

Where $\mathrm{X}$ is the set of explanatory variables that include recognition and behavior, price, and socio-demographic characteristic variable. WTP can be represented by the integral of the cumulative distribution function of $\Delta \mathrm{V}$ :
$\mathrm{WTP}=\int F(\Delta \mathrm{V}) \mathrm{dt}=-\beta \mathrm{t}^{-1}[1+e(-\beta X)]^{-1}$

where $t$ is the price variable which is the amount suggested in the discrete-choice question. As a measure of WTP for seafood traceability system, the mean is calculated to figure out the value of WTP under the assumption that distribution is not skewed (Duffield and Patterson, 1991).

\section{Survey and data}

\section{Survey design}

The CV method utilizes survey techniques to ask respondents about the value of nonmarket goods (Ajzen and Driver, 1992). In this study, the survey was designed to provide respondents with general information about the seafood traceability system to enable them to construct a hypothetical market. It described the definition of seafood traceability, and the benefit in terms of consumption-oriented information (transparency throughout channels of distribution and process, efficient determination of the cause of accidents, and rapid recall of items) and production-oriented information (quality control, sanitation management, and understanding customer spending patterns through accumulation of information). After a brief explanation about the system, several questions asked respondents to state the level of their preference and consumption of seafood, and how they think of the system. Then, for evaluation of the system, the survey constructed a hypothetical market, presenting a scenario: if the government were to establish and maintain the traceability system, people would benefit in terms of food safety from the system. In order for the government to maintain the traceability system, taxpayer money will be required. Each household would have to pay X Korean Republic won (KRW) each year in taxes. It is also necessary to determinate how to elicit respondents' WTP, considering that it comes from the response to a hypothetical question (Hoyos and Mariel, 2010). While the elicitation method may take the form of an open-ended question or a dichotomous question (Champ et al., 2003), this study uses the dichotomous method. The respondent is required to respond yes/no to the given amount for the goods in the dichotomous approach. A dichotomous question is easy to respond to because it is based on intuitive judgment and choice, and the method is relatively similar to actual market transactions, so that the respondent can feel familiar with the hypothetical market (Whitehead et al., 1998). The dichotomous choice method is commonly used in $\mathrm{CV}$, as the open-ended choice 
method and ratio-level response have become debatable due to the possibility of erratic results (Champ et al., 2003).

This paper utilizes the single bounded and double bounded dichotomous choice methods. For the double bounded method, the statistical efficiency can be improved by asking the respondent to engage in two rounds of bidding: participants respond to an initial price amount and then face a second question involving another price amount, higher or lower depending on the response to the first question. There are five amounts in the set of $\operatorname{tax}(2,7,10,13,18)$, and the set is based on the result of the pilot test. Each survey suggests the amount of tax randomly assigned among the sets. The respondents were asked about their WTP again, doubling the tax if they gave a yes response and reducing the tax by half if they gave a no response. Respondents who answered no were also asked to indicate the reason they were not willing in order to ascertain if there is purpose for the protest.

\section{Survey data}

The survey was conducted in Seoul and Busan between March and April 2019. Seoul and Busan, which are the two biggest cities in Korea, were selected as they represent on inland city and a port city, respectively. The survey was conducted among respondents aged over 20, and the sample was allocated in proportion to each city's population since there is a difference between populations of the two cities. In order to examine sociodemographic characteristics, respondents were asked to indicate both individual and household characteristics when filling out the questionnaire. A total of 959 respondents were included in the sample after removing protest responses and those missing values. The sample comprised 719 respondents from Seoul and 240 from Busan, of which $48.5 \%$ were men and $51.5 \%$ women. The majority of respondents are college graduates
(67.1\%). Respondents were relatively evenly distributed across age groups: 20s (25.4\%), $30 \mathrm{~s}(25.0 \%), 40 \mathrm{~s}(25.1 \%), 50 \mathrm{~s}(18.3)$, and $60 \mathrm{~s}(16.2 \%)$. The interval between 4 million KRW and 5 million KRW (17.5\%) is the highest frequency in terms of household monthly income and the interval between 3 million KRW and 4 million KRW (17.2\%) was second highest.

The variables can be classified into three groups: recognition and behavior, sociodemographic characteristics, and price variable (Table 1). Recognition and behavior of respondents covers how often respondents purchase seafood, and whether respondents care about the information that the seafood traceability system provides. Variables related to information are constructed according to the functions of the seafood traceability system - consumer function and producer function - which are defined by the MOF. The first variable is the response to the following question: If the seafood traceability system works, it becomes easier to recall contaminated products when accidents occur due to the information provided by traceability. Do you think it is worth keeping this function of the seafood traceability system? The second variable is the response to the following question: If the seafood traceability system works, producers can obtain the pattern of consumption and they can control the quality and sanitary information. Do you think it is worth keeping this function of the seafood traceability system? Socio-demographic characteristic variables include age, gender, education level, and income variable. The income variable is household monthly income and the unit is 1 million Korean won, which equals 833.33 US dollar (USD). The price variable, which is usually termed the bid in the CV method, is the amount of tax suggested and the unit is 1 thousand Korean won, which equals 0.83 USD.

\section{Results}

The analysis of the seafood traceability system was carried out by estimation using two approaches: i) estimation of the model with no covariates and ii) estimation of the model with covariates. In the first approach, a regression of the dependent variable on the price factor (i.e., tax) without including other covariates was performed. The results are presented in Table 2. In this approach, the model is a kind of null model, but it can estimate the respondents' WTP. It is meaningful in that it serves as a benchmark for other models. The results of goodnessof-fit in both the single bounded and double bounded methods demonstrate that the model fits a given data set as each Wald chisquare is statistically significant at the $1 \%$ level. Each TAX variable, which the represents price factor, is statistically significant and negative. The negative coefficient values of the variable represent the economic principle that demand for goods is inversely proportional to price.

In the second approach, AGE, GNDR, FREQ, INFO1, INFO2, INC and EDUC are included in the model as explanatory variables, as presented in Table 3 . The model does not have problem with goodness-of-fit, and the results reveal the single bounded and double bounded methods fit to the data as the Wald chi-square is statistically significant. Coefficients on TAX are statistically significant and negative, as is the case in the no covariates model. It is considered that preference and recognition factors affect respondents' WTP as the relevant variables are statistically significant. The coefficients on FREQ in both the single bounded and double bounded methods are positive, suggesting that those who buy seafood more frequently appreciate the seafood traceability system. The coefficients on INFO1 and INFO2 are also positive, suggesting that

Table 1. Definition of variables and data summary.

\begin{tabular}{|c|c|c|c|c|}
\hline & Variable & Definition & Mean & Std. Dev. \\
\hline \multirow[t]{3}{*}{ Recognition and Behavior } & FREQ & $\begin{array}{l}\text { frequency of seafood purchase } \\
\text { Likert scale: } 1 \text { (almost never) to } 9 \text { (daily) }\end{array}$ & 5.9135 & 1.6549 \\
\hline & INFO1 & 1 if information of consumer side is important for respondent, 0 otherwise & 0.9729 & 0.1625 \\
\hline & INFO2 & 1 if information of producer side is important for respondent, 0 otherwise & 0.9552 & 0.2071 \\
\hline Socio-demographic & AGE & age in years of respondent & 39.7987 & 11.6993 \\
\hline \multirow[t]{5}{*}{ Characteristic } & GNDR & gender of respondent & & \\
\hline & & ( 1 if respondent is male, 0 otherwise) & 0.4849 & 0.5000 \\
\hline & EDUC & education level of respondent & 2.9771 & 0.5103 \\
\hline & & $\begin{array}{l}\text { (1: middle school, 2: high school, } \\
\text { 3: undergraduate, 4: graduate school) }\end{array}$ & & \\
\hline & INC & $\begin{array}{l}\text { monthly income of household } \\
\text { unit: } 1 \text { million KRW ( } 833.33 \text { USD) }\end{array}$ & 5.0730 & 1.9160 \\
\hline Price (bid) & TAX & the amount suggested respondent in the discrete-choice question. unit: 1,000 KRW (0.83 USD) & 9.8916 & 5.4171 \\
\hline
\end{tabular}

The basic exchange rate is 1200 (i.e., 1 USD is equal to $1200 \mathrm{KRW}$ ) as of Sep 27, 2019. 
those who identify consumer or producer information, which are functions of the seafood traceability system, as important have higher WTP. It is considered that these factors significantly affect WTP, since the coefficients are relatively higher compared to other variables.

The income coefficients are positive and statistically significant. This means the higher income, the higher the WTP, which is supported by the income effect in economics: the demand for goods is proportional to income. Other demographic variables such as GNDR and EDUC are statistically insignificant, so it is difficult to say that there is a direct correlation between demographic factors and WTP. This implies that individual recognition and preference are intimately related to the seafood traceability system rather than demographic factors. It is noteworthy that the AGE variable is statistically significant in the double bounded method. It is considered that WTP is inversely proportional to age, as AGE is negative. Thus, it can be inferred that young people tend to value food safety when they purchase seafood while those who are older tend to value other features such as price and flavor, since the survey results reveal that the rate of placing a priority on price or flavor is proportional to age.

The results of the WTP by model are presented in Table 3. They reveal that estimates are higher in the no covariates analysis and the values from the bounded model are slightly higher compared to those of the double bounded model. The estimated WTP for the seafood safety system ranges from $\$ 8.58$ to $\$ 9.88$ and all values are statistically significant at the $1 \%$ level. The estimated mean WTP is \$9.17, while 95\% confidence interval indicates $\$ 7.88$ at the lower bound and $\$ 10.45$ at the upper bound.

According to the Korean Statistical Information Service, there were 1,115,744 households in Seoul and 3,784,490 households in Busan in 2015. Converting the result to annual benefits of Seoul and Busan by the product of the number of households and estimated WTP, it is calculated that approximately $\$ 44.94$ million can be generated annually from the seafood traceability system.

\section{Discussion}

One of the challenges of the seafood traceability system is lack of participation by producers. This is caused by production cost. While it is comparatively easy to label fisheries' products at shipment since only pallet-level traceability is required at this stage, product subdivision is inevitable over the course of the value chain, so item level labeling becomes difficult and costly due to the small size of the fish and too many markets (Shin, 2018). Hence, there is no motivation for businesses to participate in the system because it leads to an increase in production cost.

The seafood traceability system in Korea is, in effect, a voluntary system, but since policy is driving toward a mandatory system, businesses will need to comply with the system at some point. Producers need to develop a way to use the seafood traceability system as means of increasing productivity by understanding trends and patterns of consumption and maintaining product quality, leading to a high degree of adaptability in the new environment, and moving to wider participation in the system. From the standpoint of government, the provision of incentive is considered one of the ways to induce businesses to participate in the system. Since the seafood traceability system generates a certain level of benefits, as the analysis results demonstrate, government spending is acceptable within a similar level to benefit the development of the system.

The other challenge of the seafood traceability system is consumers' lack of recognition. The seafood traceability system in Korea has been developed but many people still do not know that the system is in operation and a considerable number of

Table 2. Results: model with covariates.

\begin{tabular}{llllll} 
Variable & $\begin{array}{l}\text { Single Bounded } \\
\text { Estimate }\end{array}$ & $\begin{array}{l}\text { Double Bounded } \\
\text { Std. Err. }\end{array}$ & Z value & Estimate & Std. Err. \\
Intercept & $-1.8527^{* * *}$ & 0.4659 & -3.98 & $-1.6533^{* * *}$ & 0.6295 \\
& $\left(0.4430^{* * *}\right)$ & $(0.0859)$ & $(5.16)$ & $\left(1.2384^{* * *}\right)$ & $(0.0756)$ \\
TAX & $-0.0419^{* * *}$ & 0.0078 & -5.36 & $-0.1324^{* * *}$ & 0.0053 \\
& $\left(-0.0373^{* * *}\right)$ & $(0.0076)$ & $(-4.92)$ & $\left.-0.1274^{* * *}\right)$ & $0.0051)$ \\
\hline AGE & -0.0032 & 0.0036 & -0.88 & $-0.0168^{* * *}$ & 0.0052 \\
GNDR & -0.1169 & 0.0842 & -1.39 & -0.0826 & 0.1200 \\
\hline FREQ & $0.0894^{* * *}$ & 0.0266 & 3.36 & $0.1239^{* * *}$ & 0.0384 \\
INFO1 & $0.9523^{* * *}$ & 0.3242 & 2.94 & $1.4866^{* * *}$ & 0.4467 \\
\hline INFO2 & $0.7479^{* * *}$ & 0.2396 & 3.12 & $0.7027^{* *}$ & 0.3164 \\
INC & $0.0845^{* * *}$ & 0.0229 & 3.70 & $0.1317^{* * *}$ & 0.0334 \\
EDUC & -0.0264 & 0.0846 & -0.31 & 0.0451 & -14.297 .069 \\
\hline Log Likelihood & -61.930 .813 & & & $58.82^{* * *}$ & 0.1211 \\
Wald Chi-Square & $78.28^{* * *}$ & & &
\end{tabular}

Table 3. WTP by model.

\begin{tabular}{llllll} 
Model & WIP & Std Err & Z value & \multicolumn{2}{c}{ Aggiregate WiP } \\
SB & & & $11.08(10.23)$ & $10,869,346$ & $36,867,713$ \\
DB & $9.600(9.884)$ & $1.0396(1.1593)$ & $21.87(21.40)$ & $9,597,816$ & $32,554,814$ \\
\hline Mean & $8.575(8.629)$ & $0.4705(0.4840)$ & & $10,233,581$ & $34,711,263$ \\
\hline
\end{tabular}

SB, single bounded; DB, double bounded; estimate of no covariates in parentheses; unit of calculated WTP is USD. 
consumers do not know how to use the system even though they have heard about it. Consequently, it is necessary to raise awareness of the system by focusing efforts on an awareness and education campaign. Estimating the value change based on the analysis outlined in this paper, the utility of the system and benefits that consumers recognize increase as consumers appreciate the awareness and importance of information. The improvement in the awareness of the importance of information brings about the effect of an increase in the value of the system of between 0.51 USD and 1.27 USD by the output of model, assuming increase in coefficient of INFO variables. The rise in the value of the seafood traceability system will make a positive contribution to the vitality of the system in the longer run. Thus, if the Korean government wants to activate the system, promoting information can be one of the top strategic priorities.

\section{Conclusions}

The Korean government seafood traceability has not worked well, compared to other major seafood consuming countries. However, the Korean government is planning to convert the system, which has been operated on a voluntary basis, to a mandatory system, taking notice of applicability of the system as a part of securing improved food safety. This paper examined the value of the seafood traceability system by applying the $\mathrm{CV}$ method and focusing on awareness of food safety value, represented by recognition of the importance of the information that the seafood traceability system provides. The result of the study show that Korean consumers positively assess the functions and benefits of a seafood traceability system and it is estimated that approximately $\$ 44.94$ million can be generated annually from the system. Hence, seafood traceability can be worthy of maintaining the system, particularly in terms of the consumers.

In practice, seafood traceability gives consumers a sense of security over and lowers the risk of poor food safety by providing information on the source of seafood. Thus, the value of seafood traceability is predominant in the provision of information. With $90 \%$ of respondents identifying themselves as seafood lovers, it is plausible that seafood is a staple food item in Korea and the fact that information related to food safety is a matter of consequence to Korean people is persuasive. More than half the respondents indicated they check placeof-origin when they purchase seafood and take it into consideration when deciding to buy or not. This implies that Korean consumers are influenced by information about the product in some way. However, despite the significance and benefits of the seafood traceability system, it is still not well-known in Korea, and as such, is underutilized. Paradoxically, people have a positive awareness of provision of information on seafood and think it is necessary to maintain a system like seafood traceability. This implies that there is a gap between necessity and utilization of the seafood traceability system, and the gap can be filled by making the existence and role of the system known. The revitalization of the seafood traceability system is needed, but it should be accompanied by an increase in consumer awareness through promotion about the existence of the system. To improve the awareness of seafood traceability, the government and private business organizations related to fisheries need to promote the function and benefit of seafood traceability. To do so, mass media advertising campaign about seafood traceability should be combined with education on food safety. It also requires information about its use in increasing convenience of consumers. For example, easy access to related website or development of well-designed mobile app can contribute to consumer-friendly traceability. Finally, the system should be well-organized so that consumers will not feel uncomfortable using the system and also the assessment of awareness of seafood traceability has to be carried out regularly.

\section{References}

Ajzen I, Driver BL, 1992. Contingent value measurement: On the nature and meaning of willingness to pay. J Consumer Psychol 1:297-316.

Borit M, Olsen P, 2012. Evaluation framework for regulatory requirements related to data recording and traceability designed to prevent illegal, unreported and unregulated fishing. Marine Policy 36:96-102.

Boyle KJ, Johnson FR, McCollum DW, 1997. Anchoring and adjustment in single-bounded, contingent-valuation questions. American Journal of Agricultural Economics 79:1495-500.

Caswell JA, 1998. Valuing the benefits and costs of improved food safety and nutrition. Austr J Agr Resour Ec 42:40924.

Champ PA, Boyle KJ, Brown TC, eds, 2003. A primer on nonmarket valuation. Dordrecht: Kluwer Academic Publishers.
Duffield JW, Patterson DA, 1991. Inference and optimal design for a welfare measure in dichotomous choice contingent valuation. Land Ec 67:22539.

FAO, 2018. Contributing to food security and nutrition for all. Rome: FAO.

Fricker S, Galesic M, Tourangeau R, Yan T, 2005. An experimental comparison of web and telephone surveys. Public Opinion Quarterly 69:370-92.

He J, 2018. From country-of-origin labelling (COOL) to seafood import monitoring program (SIMP): How far can seafood traceability rules go? Mar Policy 96:16374.

Hoyos D, Mariel P, 2010. Contingent valuation: Past, present and future. Prague Econ Pap 4:329-43.

Leal MC, Pimentel T, Ricardo F, Rosa R, Calado R, 2015. Seafood traceability: current needs, available tools, and biotechnological challenges for origin certification. Trends Biotechnol 33:3316.

MOF, 2015. Survey for awareness of the seafood traceability system and promotion: final report. Korea: Focus Company.

MOF, 2016. Study on Application of Foreign Seafood Certification System. Korea; Aqua International.

MOF, 2018. First step to mandatory seafood traceability system. Press release: Oct. $26^{\text {th }}, 2018$. Accessed: August $10^{\text {th }}, 2019$. Available from: http://www.mof.go.kr/article/view.do?ar ticleKey $=23717 \&$ boardKey $=10 \&$ menu Key $=376 \&$ currentPage $\mathrm{No}=1$

MOF, 2018. Fisheries production and fisheries industry: final report. Korea: MOF.

Pramod G, Nakamura K, Pitcher TJ, Delagran L, 2014. Estimates of illegal and unreported fish in seafood imports to the USA. Mar Policy 48:102-13.

Shin Y, 2018. A Study on the State and Development of Seafood Traceability System in Korea. J Marit Bus 40:93114.

Van Rijswijk W, Frewer LJ, Menozzi D, Faioli G, 2008. Consumer perceptions of traceability: A cross-national comparison of the associated benefits. Food Qual Prefer 19:452-64.

Whitehead JC, Huang JC, Blomquist GC, Ready RC, 1998. Construct validity of dichotomous and polychotomous choice contingent valuation questions. Environ Resur Econ 11:107-16.

Yasuda T, Bowen RE. Chain of custody as an organizing framework in seafood risk reduction. Mar Pollut Bull 53:640-9 